\title{
The Communicative Function of English Parenthetical Constructions
}

\author{
Marine Yaghubyan \\ Yerevan State University
}

\begin{abstract}
The main function of parenthetical constructions is to characterize the sentence from the position of the speaker to the listener. In English parenthetical constructions are essential, since they not only connect ideas, sentences, paragraphs making them more cohesive, but also introduce contrast or opposition, emphasis or agreement, purpose, result or conclusion, etc.

We try to demonstrate how parenthetical constructions provide and convey communicative functions in spoken and written discourse. However, one should also note that parenthetical constructions cannot carry out the communicative shifts independently; hence the certain communicative shift is relatively dependent on the context.
\end{abstract}

Key words: parenthetical constructions, communicative competence, communicative function, communicative skill.

\section{Introduction}

The primary function of a language is to convey information to each other. Different contexts require different kinds of vocabulary and different expressions that are suitable to that particular context. However, people do not only give information of a concrete nature to each other that has some inherent "truth" about it but also they put their own evaluation on the information to either create an entertaining or an emotive story, a convincing argument, a diplomatic inquiry and so on. Such "evaluation" then provides an interpersonal aspect to the discourse and provides a starting point from which a conversation partner might decide to agree or disagree, or at least to have a 
reaction that might promote a social encounter. Language is purposefully used to engage others as well as simply to convey certain types of information. Speakers can construe their own identity and authority and choose to align or disalign themselves with potential conversation partners through their choice of words and particular grammatical constructions (Huston, Merrigan 2000:15).

Another function of a language is to create coherent messages. For discourse to hang together in a logical and organized way, certain linguistic devices such as conjunctions and parenthetical constructions (e.g. however, therefore) are used. Communication will break down if there is no continuity or coherence to a speaker's discourse. This occurs during both monologue and dialogue. In monologue, the speaker must maintain coherence within his or her own discourse, while in dialogue, he or she must be able to continue on from the previous speaker, using similar vocabulary, referring to what has just been said, and developing the topic.

Thus, grammatical competence is a part of communicative competence (Huston, Merrigan 2000:21). Therefore, to acquire an effective communicative skill, people should pay attention to grammar due to the following reasons.

First, grammar is very important because it may help to enhance accuracy. Accuracy in communication forms the mind to habits of order and clearness, it accustoms learners to accuracy of language, and hence, to accuracy of thinking. This means grammar rules can help learners develop a habit of thinking logically and clearly. Therefore, after studying grammar, they will become more accurate when using language.

Communicative grammar accuracy improves the development of fluency. The person will know how to organize and express the ideas in his/her mind in a smooth way.

Second, a proper use of grammar is a sign of respect, both for speakers and listeners. For speakers, speaking clearly means they take time to polish themselves with a good impression from listeners. For listeners, a proper use of grammar shows that their thought is concerned. 
The role of parenthetical constructions in communication is of paramount importance. The main function of the parenthetical constructions is to characterize the sentence from the position of the speaker to the listener (Alexandrova 1984:34). Parenthetical constructions and their appropriate usage are vital devices for any kind of communication: written or oral. These constructions provide cohesion between sentences and paragraphs, they give logical organization and structure to the context or text, and they make the text easier to read.

\section{Parenthetical Constructions Marking Support and Emphasis}

In English parenthetical constructions are essential, since they not only connect ideas, sentences, paragraphs making them more cohesive, but also they show contrast or opposition, emphasis or agreement, purpose, result or conclusion etc.

After identifying the importance of parenthetical constructions in communication, we now try to demonstrate how parenthetical constructions provide and communicative functions in spoken and written discourse. They can mark support and emphasis. To cue the stated communicative shifts to the reader: the following lexical patterns come in handy: in other words, for one thing, in this case, for this reason, to put it another way, that is to say, by all means, another key point, first thing to remember, on the positive side, on the negative side, with this in mind, namely, chiefly, truly, indeed, certainly, surely, markedly, especially, surprisingly, significantly, particularly, in fact, in particular, in detail, for example, for instance.

In the following passage, the author used the parenthetical construction indeed in order to create a link between his idea and the reality, as well as to demonstrate his agreement and awareness in regard to reality. Hence, the parenthetical construction indeed is a marker of agreement and emphasis. E.g.:

"Indeed, it is not uncommon for slaves even to fall out and quarrel among themselves about the relative goodness of their masters, each 
contending for the superior goodness of his own over that of the others".

(Douglass 1981:78)

A way to express similarity is to attach parenthetical constructions of similarity, which reflect resemblance. In the examples mentioned below, the writers use the words similarly, likewise to show the relationship between the statements, as well as to support the given ideas. So, we can see that these parentheticals serve as a marker of similarity in the following examples. E.g.:

"In time of the cholera, some people go about with a camphorated handkerchief to their mouths; so, likewise, against all mortal tribulations, Stubb's tobacco smoke might have operated as a sort of disinfecting agent".

(Melville 1992:27)

"It may or may not be affected by Philo; it is almost or quite solitary in the N.T. Similarly, the immortality of the soul may be maintained on Platonic or quasi-Platonic lines, as by St Athanasius".

(Melville 1992:47)

\section{Parenthetical Constructions Expressing Contradiction,}

\section{Addition with a Touch of Agreement and Consequence}

Unlike parenthetical constructions expressing similarity, certain parenthetical elements express contradiction and thus introduce a change in the line of reasoning (contrast). although, in contrast, different from, on the other hand, on the contrary, in spite of, though, then again, above all, in reality, after all, even though, although, instead, whereas, despite, conversely, otherwise, however, rather, nonetheless, regardless, notwithstanding, in addition to, this may be true, in contrast, though, as it may, in reality, after all, etc. E.g.: 
"Oh! In spite of million villains, this makes me a bigot in the fadeless fidelity of man! - and a black! and crazy! - but me thinks like-cureslike applies to him too; he grows so sane again”.

(Melville 1992:38)

"In the limit of dilution when $n$ is very small compared with $N$ this gives Raoult's experimental law that the relative lowering is $n / N$, which we deduced from the osmotic law, and conversely from which the osmotic law follows, while for more concentrated solutions agreement is obtained by assigning arbitrary values to a, which, as we have seen, is 5 in the case of cane-sugar".

(Melville 1992:44)

The parentheticals in spite of, conversely used in the examples above logically make the ideas fluent, coherent, at the same time they signal the subtle differences and contrasts that exist.

The following parenthetical elements point out addition sometimes with a touch of agreement like: this may be true, nevertheless, of course, on the same time, besides, then again, in addition and so forth. E.g.:

"You know I am trying very hard to get through with the reading for the examinations in June, and this, in addition to my regular schoolwork, keeps me awfully busy".

(Keller 1989:44)

In this example, the writer makes us feel her awful situation. She not only tries hard to get through with the reading for the examinations, but also she works, which makes her busy, thus adding more elements to her current situation. So, the parenthetical construction in addition has purely additional meaning in this context. E.g.: 
"But one thing, nevertheless, that made me a little distrustful about receiving a generous share of the profits was this: Ashore, I had heard something of both Captain Peleg and his unaccountable old crony Bildad...".

(Melville 1992:217)

Providing the parenthetical nevertheless in this paragraph is largely a matter of attitude to show agreement, to stress once more the very idea that made him a little distrustful.

The following group of parenthetical constructions serves to intensify the very idea that after a peculiar time there was/is/will be a consequence or an effect: as a result, under those circumstances, in that case, for this reason, in effect, thus, because, then, hence, consequently, therefore, forthwith, accordingly. E.g.:

"They belonged to the defendants; the whale, because it was a LooseFish at the time of the final capture; and the harpoons and line because when the fish made off with them, it (the fish) acquired a property in those articles; and hence anybody who afterwards took the fish had a right to them".

(Melville 1992:118)

In this example, the parenthetical construction hence allows the reader to establish probability and prepare accordingly.

Parenthetical Constructions of Time, Chronology and Sequence, Restatement, Conclusion and Summary

Speakers also make use of parenthetical constructions of time, chronology and sequence in order to build up the communicative function of limitation, restriction and definition of time: at the present time, from time to time, sooner or later, at the same time, up to the present time, to begin with, in due time, after a while, as soon as, as long as, in the meantime, in a moment, without delay, in the first place, suddenly, at this instant first, second, immediately, quickly, finally, after, later, last, 
until, till, since, on a sudden, then, before, hence, since, when, once, now formerly, suddenly, shortly, henceforth, whenever, eventually, meanwhile, further, during, in time prior to, forthwith, presently, occasionally. E.g.:

"After a while, the villager voices start a different chant, of nangjata, nangjata, and this gradually dominates over the forest chant..."

(Crystal 2014:28)

In this example David Crystal achieved the desired chronological effect with the help of the parenthetical construction after a while, so this construction shows that actions are presented as if they follow each other.

Parenthetical constructions are also used to express restatement, conclusion and summary: as can be seen, generally speaking, in the final analysis, all things considered, as shown above, in the long run, given these points, as has been noted, in a word, for the most part, after all, in fact, in summary, in conclusion, in short, in brief, in essence, to summarize, on balance, altogether, overall, ordinarily, usually, by and large, to sum up, on the whole, in any event, in either case, all in all, obviously, ultimately, definitely. E.g.:

"Many parents and students have been complaining about the program. For example, scores on the end-of-grade tests have gone down from last year; teachers are not very motivated; and everyone is frustrated. To sum up, some improvements in the middle school program need to be made".

(Keller 1989:48)

"There was a malfunction in the smoke machines and lights, the curtains would not open and close properly, and one of the actors was sick with no stand-in. In conclusion, the play was a disaster".

(Keller 1989:26) 
These parenthetical constructions mentioned above lead the reader to draw conclusions from the preceding thoughts.

Some parenthetical constructions mentioned above may also have another or additional communicative function depending on the context, for instance parenthetical construction for example specifies the preceding statement. With the expression for example, the writer introduces a specific example that helps to explain or confirm the general statement. To prove the above stated let us consider the following example:

"Ambiguous words or statements lead to vagueness and confusion, and shape the basis for instances of unintentional humor. For example, it is ambiguous to say "I rode a black horse in red pyjamas," because it may lead us to think the horse was wearing "red pyjamas".

(Douglass 1981:61)

Parenthetical constructions of contrast and contradiction like conversely, on the other hand, on the one hand, on the contrary, however, yet, but, etc. may also build up other communicative functions. E.g.:

"The children were very happy. On the other hand, and perhaps more importantly, their parents were very proactive in providing good care".

(Douglass 1981:83)

In this example the author not only makes a contradiction, but also compares children with parents in order to make the situation more emphatic and expressive. 


\section{Conclusion}

Thus, within the framework of communication, English parenthetical constructions are essential, since they not only connect ideas, but also can introduce contrast or opposition, emphasis or agreement, purpose, result or conclusion, etc. in the line of argument. However, one should also note that parenthetical constructions cannot carry out the communicative shifts independently; hence the certain communicative shift is relatively dependent on the context.

\section{References:}

1. Alexandrova, O.; Komova, T. (2007) Modern English Grammar. Morphology and Syntax. Moscow: Academia.

2. Blakemore, D. (2006) Divisions of Labour: The Analysis of Parentheticals. Lingua. Amsterdam: North-Holland Publishers Co.

3. Dehe, N.; Kavalova, Y. (2007) Parentheticals. Amsterdam: John Benjamins.

4. Huston, C.; Merrigan, G. (2000) Communication Research Methods. Clarendon: OUP.

\section{Sources of Data:}

1. Crystal, D. (2014) Living On. London: Fames Flefber.

2. Douglass, F. (1981) The Narrative of the Life of Frederick. Boston: American Press Inc.

3. Keller, H. (1989) The Story of My Life. New York: Doubleday Page and Company.

4. Melville, H. (1992) Moby-Dick. New York: Harpers and Brothers Publishers.

5. Morell, D. (2003) First Flood. Indiana: Indiana University Press.

6. Shakespeare, W. (1974) Henry 8. Harmondsworth: Penguin Press. 


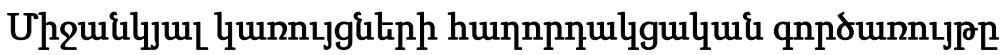

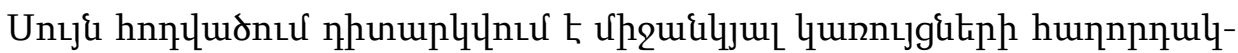

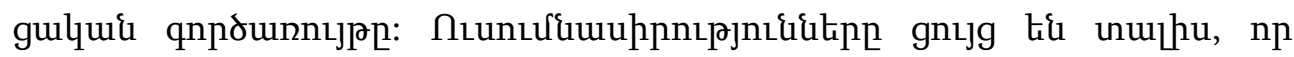

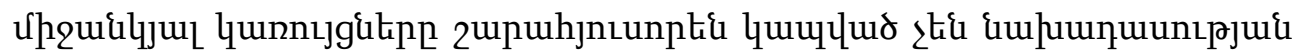

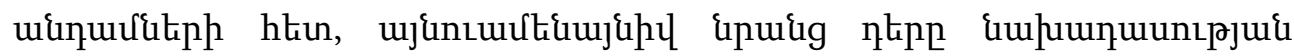

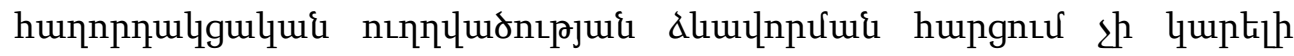

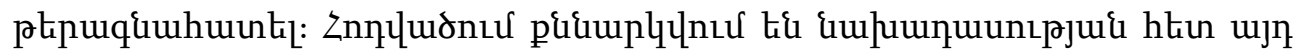

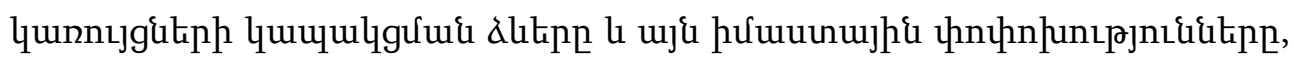

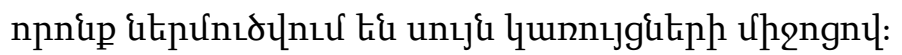

